\title{
Childhood Hypopituitarism: A Three Decades of Experience from a Major Teaching Hospital in Central Region (Riyadh) Saudi Arabia
}

\author{
Reem AH Al Khalifah ${ }^{1}$, Nasir AM Al Jurayyan*1, Rushaid NA Al Jurayyan², Mossa NA Al Motawa ${ }^{1}$, Sharifah DA Al \\ Issa $^{1}$ and Hessa MN Al Otaibi ${ }^{1}$ \\ ${ }^{1}$ Pediatric Endocrinology Division, Department of Pediatrics, College of Medicine, King Saud University, Riyadh, Saudi Arabia
}

${ }^{2}$ Radiology and Medical Imaging Department, College of Medicine, King Saud University, Riyadh, Saudi Arabia

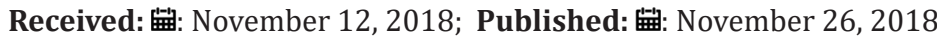

*Corresponding author: Nasir AM Al-Jurayyan, Department of Pediatrics, Professor and Consultant Pediatric Endocrinologist, Division of Endocrinology, College of Medicine, King Saud University, Riyadh, Saudi Arabia

\begin{abstract}
Childhood hypopituitarism is a clinical syndrome of deficiency in pituitary hormone production. Presentation varies from asymptomatic to acute collapse depending on the etiology, rapidity of onset and predominant hormone involved. A retrospective hospital-based cohort study was conducted at the pediatric endocrine service, King Khalid University Hospital Riyadh, Saudi Arabia (January 1989-December 2017). All the patients (total of 202 patients) who were diagnosed to have hypopituitarism, at the pediatric endocrine service, King Khalid University Hospital Riyadh, Saudi Arabia (January 1989-December 2017). A total of 202 patients were diagnosed to have hypopituitarism. Mean age was 8-9years. Beside congenital causes, diversity of acquired causes were encountered with a non-tumor causes being the commonest. Growth Hormone Deficiency (GHD) was diagnosed in 152 (70.2\%) patients. Isolated GHD in 123 patients. Multiple pituitary hormone deficiency was the diagnoses in 29 patients. Central adrenal insufficiency was present in 59(29.2\%) patients. Diabetes insipidus associated with hypopituitarism in 24(11.9\%) patients. Childhood hypopituitarism is not that rare. High index of suspension coupled with appropriate hormone assay, and head MRI are essential for management.
\end{abstract}

\section{Introduction}

The pituitary gland is a midline structure located just beneath the optic chiasm. It is composed of two main lobs, the predominant anterior lobe which is known as adenohypophysis and the posterior lobe which is known as neurohypophysis and the vestigial intermediate lobe [1]. Hypopituitarism is a clinical syndrome of deficiency in pituitary hormone production. It might be a life threating condition. It can result from disorders involving the pituitary gland, the hypothalamus or the surrounding structures, such as tumor, inflammation, infection, surgical destruction, radiation, traumatic or vascular insult. It might be associated with birth trauma and perinatal asphyxia or midline defects such as cleft lip, septo-optic hypoplasia and encephalocele. Hypopituitarism could be partial or complete insufficiency of pituitary hormone. Panhypopituitarism refer to involvement of two or more pituitary hormone. However, involvement of one hormone only refer to isolated or partial hypopituitarism. The younger the child is at the time of presentation the more likely the etiology is to be congenital. However, on occasions, congenital forms may present or get diagnosed well after birth and conversely, some children with acquired forms are discovered relatively early in life [2-8]. This article reports on the clinical experience of childhood hypopituitarism from a major teaching hospital, King Khalid University Hospital (KKUH) in the central region of Saudi Arabia over more than 25 years, January 1989 to December 2017. KKUH is affiliated to King Saud University and provides primary, secondary and tertiary health care service to the local population and receives patients' referral from all over the country.

\section{Materials and Methods}

The medical records of patients who were diagnosed to have hypopituitarism were retrospectively reviewed from January 1989 to December 2017. Data included were age, sex, clinical presentation and results of the relevant laboratory investigations and radiological images. Magnetic Resonance Imaging (MRI) was done when appropriate. The diagnosis of hypopituitarism was based on clinical suspicion suggested by the appropriate hormonal testing. The various hormonal testing to assess both the anterior and posterior pituitary gland functions, were performed following 
the specific protocol [9]. Pituitary function was evaluated after 1-2 months of any neurological procedure. Thyroid function was periodically evaluated as to monitor for thyroid dysfunction.

\section{Statistical Analysis}

Descriptive data is provided. Dichotomous data is presented as frequencies and percentage. Statistical Packages for Social Service (SPSS version 21) was used for the statistical analysis of the data.

\section{Results}

During the period under review, January 1989 and December 2017, there were 202 patients with hypopituitarism, of these, 142 $(70.3 \%)$ were males and $60(29.7 \%)$ females. The mean age was 8-9 years (range 0-18 years). MRI brain was performed in 173 (85.6\%) of patients. The clinical presentation varied from asymptomatic to symptomatic, the severity of which depends on the hormone deficient and the cause of the disorder. Birth trauma, hypoglycemia, neonatal hepatitis, optic nerve hypoplasia and other midline defects where clues to the diagnosis. Beside congenital causes, a diversity of acquired causes were encountered with a non-tumor causes being the commonest. Those included Traumatic Brain Injury (TBI), in three patients and Sub Arachnoid Hemorrhage (SAH), in one patient, central nervous system infections were in two patients, histocytosis in three patients, empty sella syndrome in one patient and various tumors in the hypothalamic pituitary region, the majority of which is craniopharyngioma, constitute 12 $(5.9 \%)$ patients in our series.

Table 1: Etiology of Growth Hormone Deficiency (GHD) in 152 patients with Magnetic Resonance Imaging (MRI).

\begin{tabular}{|c|c|c|c|c|}
\hline $\begin{array}{l}\text { Number of } \\
\text { hormones } \\
\text { affected }\end{array}$ & Diagnosis & Number & $\%$ & MRI findings \\
\hline \multicolumn{2}{|c|}{ Isolated Growth Hormone Deficiency } & 123 & 80.9 & Normal \\
\hline & Idiopathic & 111 & 90.2 & \\
\hline & Birth asphyxia & 9 & 7.4 & \\
\hline & Neurofibromatosis & 2 & 1.6 & \\
\hline & Histocytosis X & 1 & 0.8 & \\
\hline \multicolumn{2}{|c|}{$\begin{array}{l}\text { Multiple Pituitary Hormone Deficien- } \\
\text { cy }\end{array}$} & 29 & 19 & $\begin{array}{c}\text { Pituitary } \\
\text { hypoplasia or } \\
\text { aplasia }\end{array}$ \\
\hline & $\begin{array}{l}\text { Hypothalamic } \\
\text { pituitary tumor }\end{array}$ & 12 & 41.4 & \\
\hline & $\begin{array}{c}\text { Congenital } \\
\text { hypopituitarism }\end{array}$ & 6 & 20.7 & \\
\hline & Septo-optic dysplasia & 3 & 10.3 & \\
\hline & $\begin{array}{l}\text { Trumatic brain } \\
\text { injury }\end{array}$ & 3 & 10.3 & \\
\hline & Histocytosis X & 2 & 6.9 & \\
\hline & Infection & 2 & 6.9 & \\
\hline & Empty sella & 1 & 3.5 & \\
\hline \multicolumn{2}{|l|}{ Total cases } & 152 & & \\
\hline
\end{tabular}

Growth Hormone Deficiency (GHD) was the commonest deficient hormone among other hormones 152 (70.2\%) patients. Isolated Growth Hormone Deficiency (IGHD) 123 patients was more common compared Multiple Pituitary Hormone Deficiency (MPHD) in 29 patients (Table 1). Hypothalamic pituitary MRI abnormalities were seen more commonly among cases with MPHD. Central adrenal insufficiency was the second most common hormonal deficiency seen in 59 (29.2\%) (Table 2). Diabetes insipidus associated with Panhypopituitarism seen in 24 (11.9\%) patients (Table 3). Hypothyroidism presented in 14 (6.99\%) patients of these five patients were isolated hormone central hypothyroidism, while gonadotrophic hormone deficiency presented in 8 (3.9\%) patients.

Table 2: Etiology of central adrenal insufficiency in 59 patients with hypopituitarism.

\begin{tabular}{|c|c|c|}
\hline Diagnosis & Number & Percentage \% \\
\hline Hypothalamic pituitary tumor & 12 & 20.3 \\
\hline Congenital hypopituitarism & 19 & 32.2 \\
\hline Isolated ACTH1 deficiency & 3 & 5.1 \\
\hline Histocytosis-X & 3 & 5.1 \\
\hline Septo-optic dysplasia & 6 & 10.2 \\
\hline $\begin{array}{c}\text { Infection: streptococcal } \\
\text { meningitis }\end{array}$ & 2 & 3.4 \\
\hline Post-trumatic brain injury & 3 & 1.7 \\
\hline Cushing's syndrome & 1 & 16.9 \\
\hline $\begin{array}{c}\text { Drug induced glucocorticoid } \\
\text { deficiency }\end{array}$ & 10 & \\
\hline
\end{tabular}

${ }^{1}$ ACTH: Adrenocorticotrophic Hormone.

Table 3: Etiology of Central Diabetes Insipidus (CDI) in 24 patients with hypopituitarism.

\begin{tabular}{|c|c|c|}
\hline Diagnosis & Number & Percentage \% \\
\hline Brain Tumor & 11 & 45.8 \\
\hline Congenital hypopituitarism & 4 & 16.7 \\
\hline Post-trumatic brain injury & 3 & 12.5 \\
\hline Histocytosis-X & 3 & 12.5 \\
\hline Infection: streptococcal meningitis & 2 & 8.3 \\
\hline Septo-optic dysplasia & 1 & 4.1 \\
\hline
\end{tabular}

\section{Discussion}

Hypopituitarism is not that rare in children, despite that there is scant data where it is at best limited to case series. A study from Spain documented an incidence and prevalence of hypopituitarism to be 4.21 and 45.5 case per 100000 population respectively. Hypopituitarism follows a smoldering course, unless it has an onset with pituitary apoplexy, hence, more often it is likely to be missed. Hypopituitarism is often associated with increased mortality $[10,11]$. Magnetic Resonance Imaging (MRI) scan remains the modality of choice for assessing the hypothalamic pituitary region among patient with hypopituitarism. MRI scan precisely diagnose abnormality of the adenohypophysis and neurohypophysis usually the stalk. Normal pituitary MRI shows the anterior pituitary gland 
as dark structure equal in intensity to gray matter on T1-weighted imaging, while the posterior pituitary gland appears as a white structure, "bright spot" (Figure 1). The "bright spot" correlates well with the clinical presence of Diabetes Insipidus (DI) and it is completely absent in some cases of congenital hypopituitarism or it can be found ectopically located (Figure 2) in which case DI is usually absent. Such radiological findings are sometimes helpful in securing the congenital nature of hypopituitarism.
The presence of abnormality in the adenohypophysis and/or neurohypophysis carries important prognostic factor. Patients with such abnormalities usually develop MPHD compared to isolated hormonal deficiency. A spectrum of MRI findings was observed in our series ranging from normal to small or complete absent of anterior or posterior pituitary together with absence or thin stalk (Figure 3) [12].

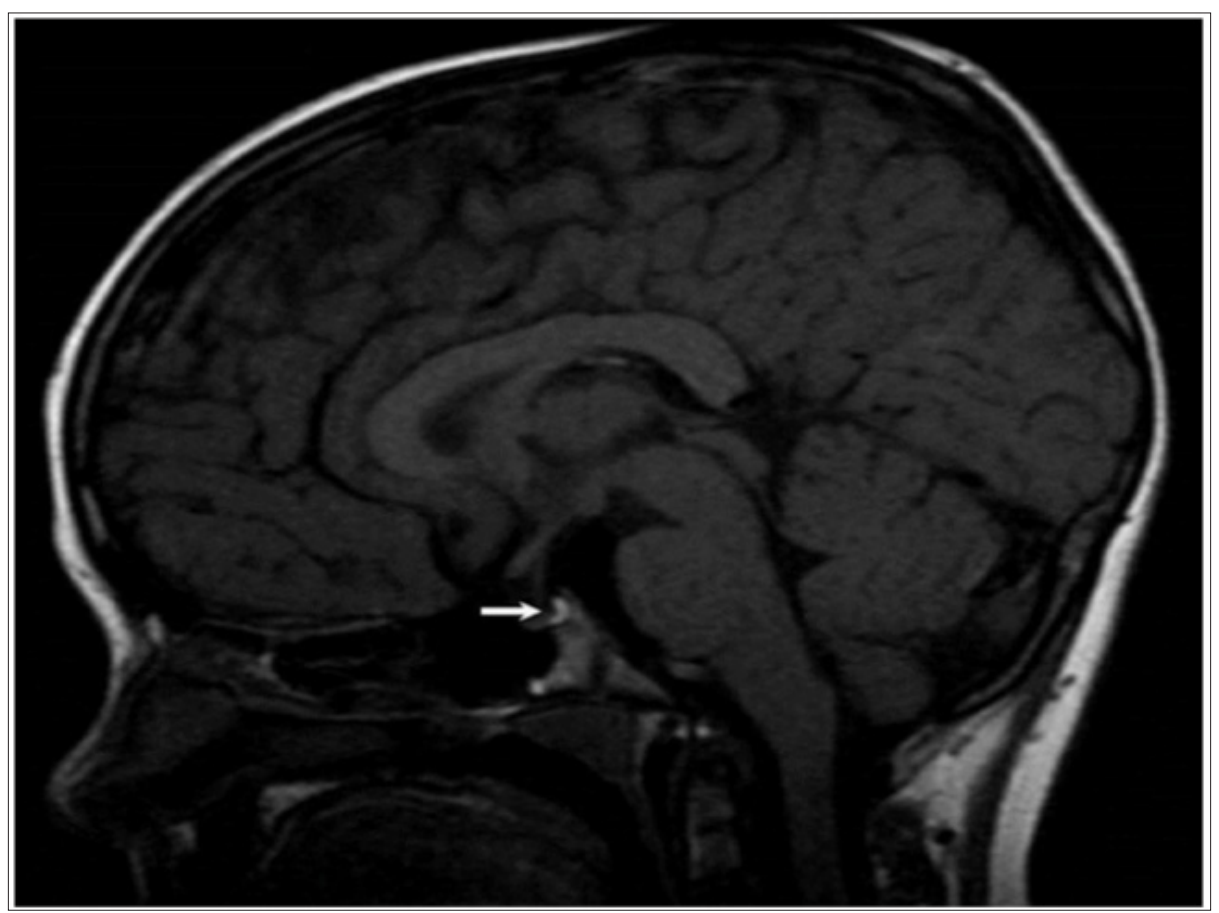

Figure 1: Sagittal T1 weighted Magnetic imaging showing a normal study.

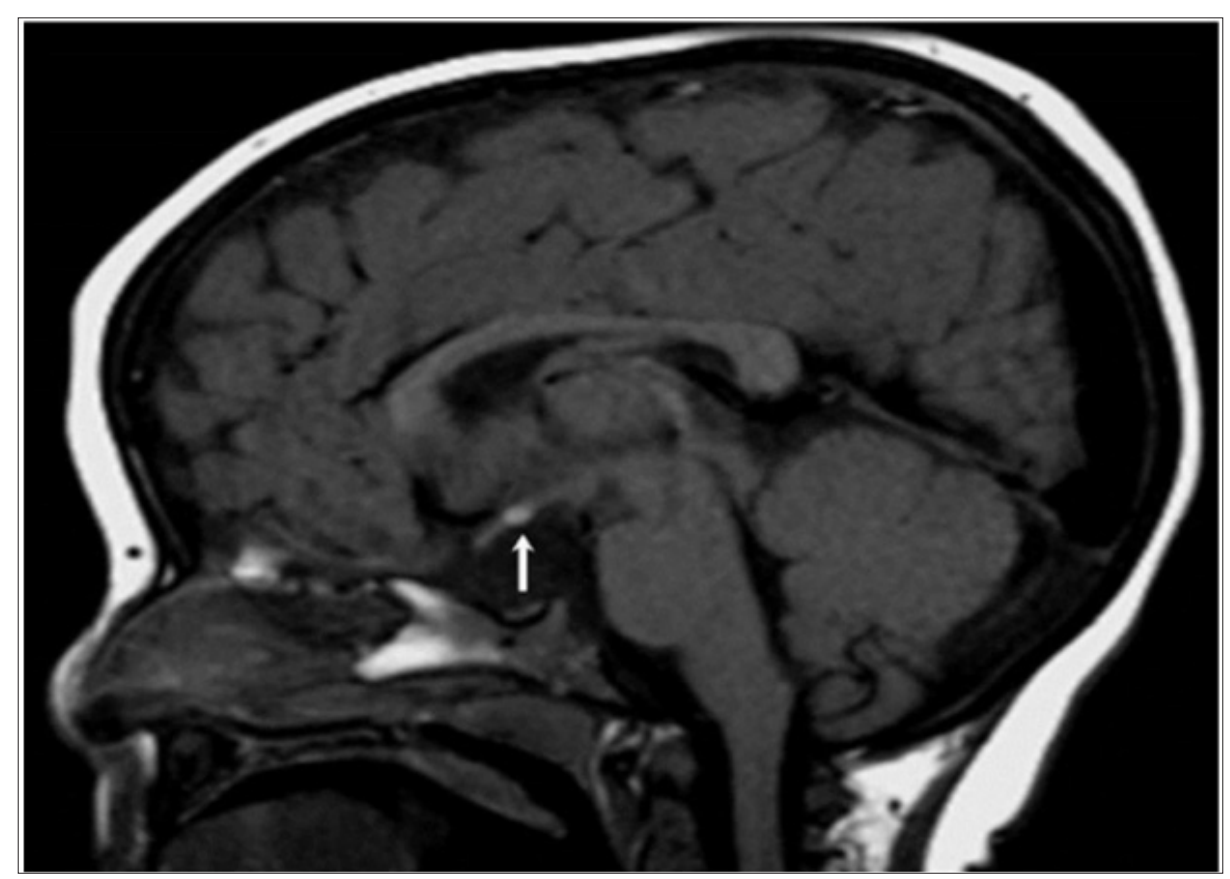

Figure 2: Sagittal T1 weighted Magnetic resonance imaging in a 2.5-year-old girl with multiple pituitary hormone deficiency showing a small anterior pituitary, absent stalk and ectopic posterior pituitary. 


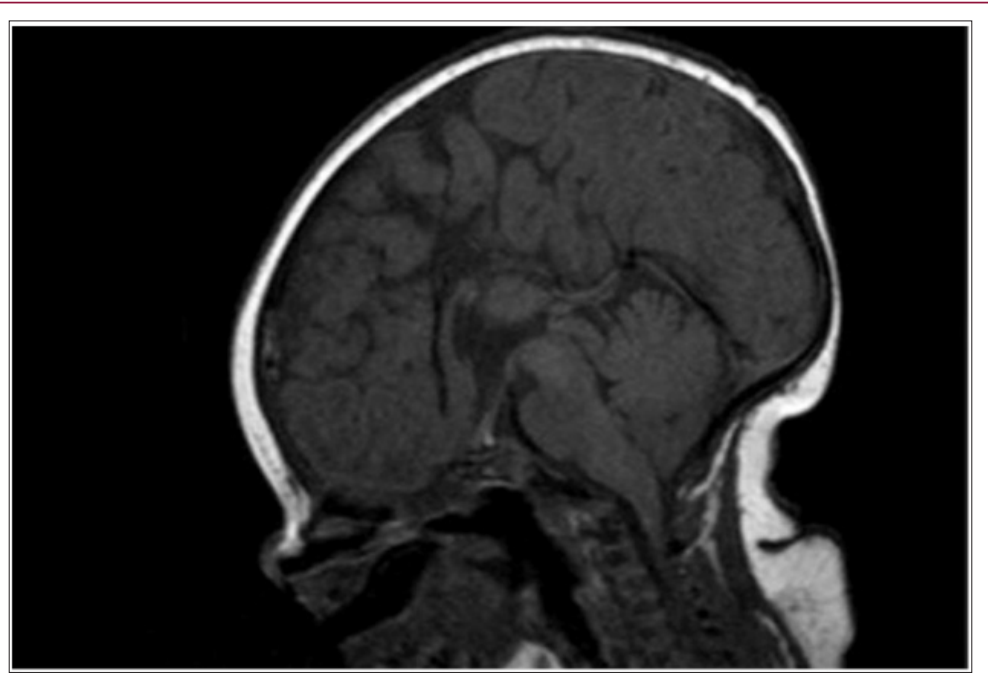

Figure 3: Mid-sagittal brain MRI: Agenesis of the dorsal portion of the corpus callosum associated to a rudimentary and hypoplastic ventral corpus callosum. Flat floor of the Sella turcica, slightly excavated with absence of visualization of the stalk and the pituitary in all sequences.

The clinical presentation varies from asymptomatic to acute collapse, depending on the etiology, rapidity of onset and predominant hormones involved [2,5,13,14]. During neonatal period and early infancy, hypoglycemia is considered the most critical presenting feature and perhaps the most common feature of congenital hypopituitarism. In some affected male, congenital hypopituitarism can present at birth as isolated microphallus therefore from isolated GH deficiency or combined GH and gonadotropin deficiency. Additionally, noninfectious hepatitis can be seen in some children with congenital hypopituitarism. This is usually suspected if there is hepatomegaly and abnormal liver enzymes predominantly indicating cholestasis and is confirmed by the presence of characteristic giant-cell transformation of hepatocytes on liver biopsy. The condition is usually self-limiting and remits over the first few months of life without permanent liver damage [15-25].

Septo-optic dysplasia, which also known as de Morsier syndrome, is the most common cause of "midline defect syndrome" in which congenital hypopituitarism is one component of this disorder. In its complete form, this syndrome combines hypoplasia or absence of optic chiasm, optic nerves or both, agenesis or hypoplasia of the septum pellucidum, corpus callosum or both (Figure 3) (the function of which is uncertain) in $50 \%$ of cases (hence, the designation,"septo") and hypothalamic insufficiency. The underdevelopment of the optic nerves is associated with variable degree of vision impairment ranging from mild loss to complete blindness.

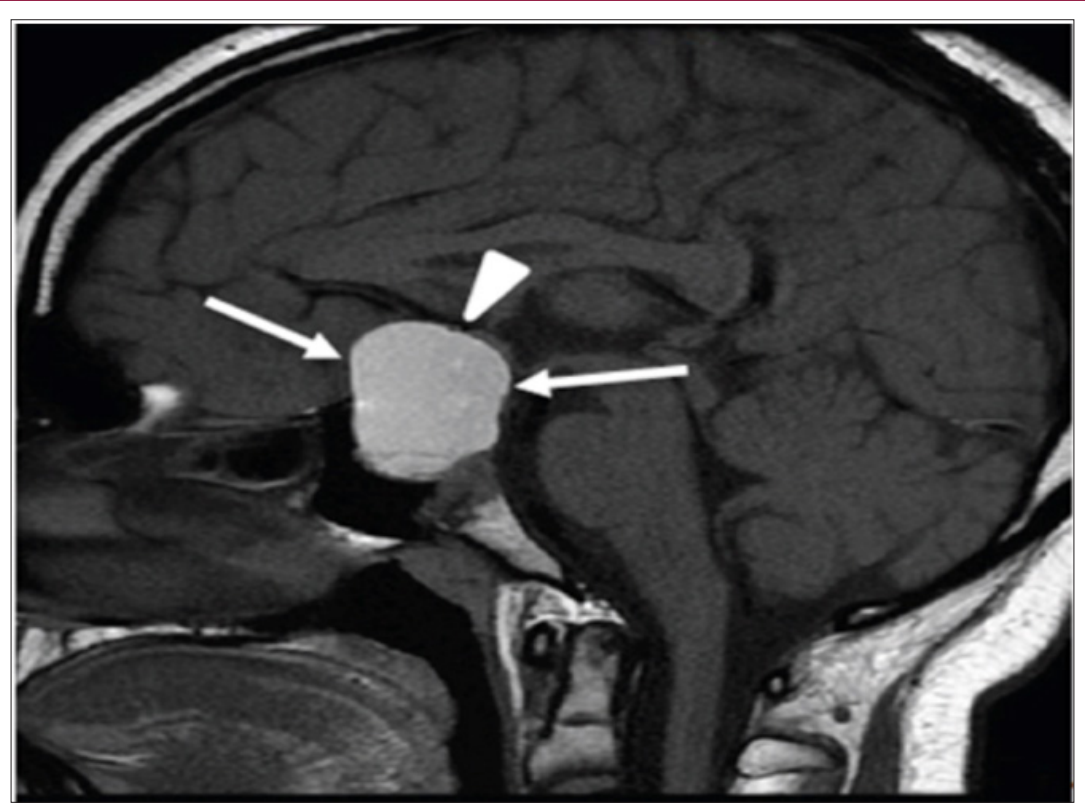

Figure 4: A 13-year-old boy with giant macroprolactinoma. Mid-sagittal brain MRI (T1 weighted image without intravenous contrast) shows a giant macroprolactinoma (arrows) with homogenous high signal intensity indicating hemorrhage. The mass is compressing on optic chiasm (arrowhead). 
Various tumors in the hypothalamic pituitary region can lead to hypopituitarism upon presentation. The majority of tumors in our series were craniopharingioma, constitute 12 (5.9\%). Commonly they present with symptoms related to mass effect of the tumor on the neighboring structures. However, other tumors in the hypothalamic pituitary region can lead to hypopituitarism such as glioma and astrocytoma. A child in our series presented with recurrent headache and visual impairment at age 13 years proved to have giant macroprolactinoma on MRI (Figure 4) [26-33]. Such findings indicate the importance and the role of pituitary and hypothalamus MRI scan in determining the cause. Langerhans Cell Histocytosis (LCH) is a rare and heterogeneous disease, characterized by accumulation and cloned proliferation of immature dendritic cells in different organs, present in $3(1.5 \%)$ of patients $[34,35]$.

Cancer survivors have a continuous risk for developing hypopituitarism even if they had a normal initial pituitary function. Surgical procedure to remove the tumor may lead to injury to the pituitary gland and result into hypopituitarism. Additionally, radiotherapy treatment for the tumors in the head and neck region may cause damage to the pituitary gland. Different hypothalamic pituitary axis has different sensitivity to radiation [36-40]. Traumatic Brain Injury (TBI) and Sub Arachnoid Hemorrhage (SAH) are being more frequently reported as etiology for hypopituitarism. The incidence of TBI 100-150 in 100,000. Posttraumatic hypopituitarism is observed in 5.4 to $40 \%$ of patient with history of TBI usually presenting as isolated deficiency in most cases. Hypopituitarism has been observed in 19\% of patient with ischemic stroke and $47 \%$ of patient with SAH presenting as an isolated deficiency in most cases. This could be due to lack of awareness [41-46]. Efforts need to be made to sensitize the clinicians about the existence of hypopituitarism in such patients.

Central nervous system infections known to have high incidence in developing countries and are known to cause hypopituitarism. In this study hypopituitarism was observed in 2 patients $(0.5 \%)$. Both of these patients developed hypopituitarism secondary to streptococcal infection [47-50]. Empty sella syndrome usually associated with pituitary hypofunction. Like other cohorts it was a rare diagnosis in our series [51-53]. Growth Hormone Deficiency (GHD), the most common hormonal deficiency and present with a wide spectrum of findings. The endocrine abnormality of GHD manifest either as an isolated deficiency (IGHD) or it may be present as Multiple Hormone Deficiency (MPHD) [54-56]. Central adrenal insufficiency accounts for the second most commonly encounters in this study, however, it is the most lethal. All except one, had multiple anterior pituitary hormone deficiency. This was present in 59 (29.3\%) patients [57-59]. One patient passed away at age 4 years from severe hypoglycemia during gastroenteritis despite that she received hydrocortisone stress dose. She was found seizing in her bed with unrecordable blood glucose. She developed cerebral edema followed by DI and passed away because of brain death. Central Diabetes Insipidus (CDI) or Anti-Diuretic Hormone $(\mathrm{ADH})$ deficiency may be associated with hypopituitarism, due to impairment of posterior pituitary gland or hypothalamus in 24
(11.9\%) patients. Patients presented with polyuria, polydipsia and high serum sodium of more than or equal $150 \mathrm{mmol} \backslash \mathrm{l}$ with diluted urine [60-62]. Furthermore, congenital isolated hypogonadotrophin is extremely rare in this study, 8 (3.9\%) patients out of 202 patients, similar to what had been reported in other cohorts [63-64].

\section{Conclusion}

This is the largest report of childhood hypopituitarism from Saudi Arabia. High Index of Suspicion coupled with timely and appropriate hormonal assay are essential for the management. A head MRI scan is critical in determining the specific etiology. It needs to be diagnosed and treated early to prevent associated mortality and morbidity. The etiology differs in childhood, as nontumor causes are common than in adults. Supervision and care by a pediatric endocrinologist is crucial and when the child grows older appropriate transition to an adult endocrinologist and experienced reproductive endocrinologist.

\section{Acknowledgement}

The authors would like to thank Mr. Abdulrahman N. Al Jurayyan for his help in preparing the manuscript.

\section{References}

1. Thorner MO, Vance ML, Horvath E (1991) The anterior pituitary In: Wilson JD, Foster DW, Williams Textbook of Endocrinology, WB Saunders, Philadelphia, USA, pp. 222-224.

2. Geffner ME (2002) Hypopituitarism in childhood. Cancer control 9(3): 212-222.

3. Kim SY (2015) Diagnosis and treatment of hypopituitarism. Endocrinol Metab (Seoul) 30(4): 443-455.

4. Gundgurthi A, Garg M, Bhardwaj R, Brar K, Kharb S, et al. (2012) Clinical spectrum of hypopituitarism in India: A single center experience. Indian J Endocrinol Metab 16(5): 803-808.

5. Van Aken MO, Lamberts SW (2005) Diagnosis and treatment of hypopituitarism: An update. Pituitary 8(3-4): 183-191.

6. Higham CE, Johannsson G, Shalet SM (2016) Hypopituitarism. Lancet 388(10058): 2403-2415.

7. Vance ML (1994) Hypopituitarism. The New England Journal of Medicine 330(23): 1651-1662.

8. Al Jurayyan NAM (2016) Congenital hypopituitarism variable presentation for the same diagnosis. IJDR 6(2): 6936-6938.

9. Bertrand J, Rappaport R, Sizonenko PC (1993) Assessment of endocrine functions. In: Bertrand J, Rappaport R, Sizonenko PC, Pediatric Endocrinology: Physiology, Pathophysiology and Clinical Aspects $\left(2^{\text {nd }}\right.$ Edn.). Baltimore, Williams \& Wilkins pp. 658-681.

10. Regal M, Paramo C, Sierra SM, Garcia-Mayor RV (2001) Prevalence and incidence of hypopituitarism in an adult Caucasian population in northwestern Spain. Clin Endocrinol 55(6): 735-740.

11. Tomlinson JW, Holden N, Hills RK, Wheatley K, Clayton RN, et al. (2001) Association between premature mortality and hypopituitarism. West midlands prospective hypopituitary study group. Lancet 357(9254): 425-431.

12. AlJurayyan RN, AlJurayyan NA, Omer HG, Rushaid NA, Sharifah DA Alissa, et al. (2017) Pituitary Imaging in 129 children with growth hormone deficiency: A spectrum of finding. Sudan J Pediatr 17(1): 30-35.

13. Ascoli P, Cavagnini F (2006) Hypopituitarism. Pituitary 9(4): 335-342. 
14. Mehta A, Dattani MT (2008) Developmental disorders of the hypothalamus and pituitary gland associated with congenital hypopituitarism. Best Pract Res Clin Endocrinol Metab 22(1): 191-206.

15. Craft WH, Underwoood LE, Van Wyk JJ (1980) High incidence of perinatal insult in children with idiopathic hypopituitarism. J Pediatr 96(3 Pt 1): 397-402.

16. Job JC (1989) Early diagnosis and early treatment of growth hormone deficiency. Horm Res 31(4): 149-152.

17. Urzola A, Leger J, Czernichow P (1999) Three cases of congenital growth hormone deficiency with micropenis and hypospadias: What does growth hormone have to do with it? Horm Res 51(2): 101-104.

18. Spray CH, McKiernan P, Waldron KE, Shaw N, Kirk J, et al. (1992) Investigation and outcome of neonatal hepatitis in infants with hypopituitarism. Acta paediatrica 89(8): 951-954.

19. Phillips Plt, Brodsky MC (2003) Congenital optic nerve abnormalities in pediatric ophthalmology and strabismus ( $2^{\text {nd }}$ Edn.). Springer Verlag Inc pp. 918-922.

20. Siatkowski RM, Sanchez JC, Andrade R, Alvarez A (1997) The clinical, neuroradiographic and endocrinologic profile of patients with bilateral optic nerve hypoplasia. Ophthalmology 104(3): 493-496.

21. Al Jurayyan NAM (2015) Neonatal cholestasis: Beyond thyroid hormones. Basic Res J Med Ckin Sci 4(10): 237-239.

22. Akin MA, Kurtoglu S, Sarici D, Akin L, Hatipoglu N, et al. (2014) Endocrine abnormalities of patients with cleft lip and/or cleft palate during the neonatal period. Turk J Med Sci 44(4): 696-702.

23. Lovinger RD, Kaplan SL, Grumbach MM (1975) Congenital hypopituitarism associated with neonatal hypoglycemia and microphallus: Four cases secondary to hypothalamic hormone deficiencies. The Journal of pediatrics 87(6 Pt 2): 1171-1181.

24. Salisbury DM, Leonard JV, Dezateux CA, Savage MO (1984) Micropenis: An important early sign of congenital hypopituitarism. Br Med J (Clin Res Ed) 288(6417): 621-622.

25. Dutta P, Gupta P, Singh P, Modi M, Srinivasan A, et al. (2015) Extra-pituitary birth defects may predict diagnosis of congenital hypopituitarism in a short child. J Assoc Physicians India 63(8): 28-36.

26. Al Hemyani DK, Al Kalifah RH, Al Twejeri IS, Al Jurayyan RN, Al Jurayyan NA (2018) Giant prolactinoma: a case report and review of the literature. Forthcoming.

27. Dutta P, Bhansali A, Singh P, Rajput R, Khandelwal N, et al. (2009) Congenital hypopituitarism: Clinico-radiological correlation. J Pediatr Endocrinol Metab 22(10): 921-928.

28. Maghnie M, Lindberg A, Koltowska-Haggstrom M, Ranke MB (2012) Magnetic resonance imaging of CNS in 15,043 children with GH deficiency in KIGS (Pfizer International Growth Database). Eur J Endocrinol 168(2): 211-217.

29. Di Iorgi N, Allegri AE, Napoli F, Bertelli E, Olivieri I, et al. (2011) The use of neuroimaging for assessing disorders of pituitary development. Clinical endocrinology 76(2): 161-176.

30. Maghnie M, Ghirardello S, Genovese E (2004) Magnetic resonance imaging of the hypothalamus-pituitary unit in childrensuspected of hypopituitarism: Who, how and when toinvestigate. Journal of endocrinological investigation 27(5): 496-509.

31. Root AW, Martinez CR (1992) Magnetic resonance imaging in patients with hypopituitarism. Trends in endocrinology and metab 3(8): 283 287.

32. Garel C, Leger J (2007) Contribution of magnetic resonance imaging in non-tumoral hypopituitarism in children. Horm Res 67(4): 194-202.

33. Tsai SL, Laffan E, Lawrence S (2012) A retrospective review of pituitary MRI findings in children on growth hormone therapy. Pediatric radiology 42(7): 799-804.
34. Vaiani E, Malossetti C, Vega LM, Zubizarreta P, Braier J, et al. (2017) Predictor variables of developing anterior pituitary deficiencies in a group of paediatric patients with central diabetes insipidus and langerhans cell histiocytosis. Hormone research in paediatrics $87(1)$ 51-57.

35. Amato MC, Elias LL, Elias J, Santos AC, Bellucci AD, et al. (2006) Endocrine disorders in pediatric - onset langerhans cell histiocytosis. Horm Metab Res 38(11): 746-751.

36. Darzy KH (2009) Radiation-induced hypopituitarism after cancer therapy: Who, how and when to test. Nat Clin Pract Endocrinol Metab 5(2): 88-99.

37. Babiker AM, Edrees A, Al Gadi I, Al Issa SD, Al Jurayyan NAM, et al. (2015) Suprasellar brain tumours related endocrinopathies. ESPE Abstracts 84: 3-824.

38. Lafferty AR, Chrousos GP (1999) Pituitary tumors in children and adolescents. J Clin Endocrinol Metab 84(12): 4317-4323.

39. Karavitaki N, Cudlip S, Adams CB, Wass JA (2006) Craniopharyngiomas. Endocr Rev 27(4): 371-397.

40. De Marinis L, Fusco A, Bianchi A, Aimaretti G, Ambrosio MR, et al. (2006) Hypopituitarism findings in patients with primary brain tumors 1 year after neurosurgical treatment: preliminary report. Journal of endocrinological investigation 29(6): 516-522.

41. Altard C, Vella S (2005) Hypopituitarism following traumatic brain injury. Malta Med J 27(4): 38-43.

42. Ghigo E, Masel B, Aimaretti G, Leon-Carrion J, Casanueva FF, et al. (2005) Consensus guidelines on screening for hypopituitarism following traumatic brain injury. Brain injury 19(9): 711-724.

43. Kokshoorn NE, Smit JW, Nieuwlaat WA, Tiemensma J, Bisschop PH, et al. (2011) Low prevalence of hypopituitarism after traumatic brain injury: A multicenter study. Eur J Endocrinol 165(2): 225-231.

44. Aimaretti G, Ambrosio MR, Di Somma C, Fusco A, Cannavo S, et al. (2004) Traumatic brain injury and subarachnoid haemorrhage are conditions at high risk for hypopituitarism: Screening study at 3 months after the brain injury. Clinical endocrinology 61(3): 320-326.

45. Benvenga S, Campenni A, Ruggeri RM, Trimarchi F (2008) Clinical review 113: Hypopituitarism secondary to head trauma. J Clin Endocrinol Metab 85(4): 1353-1361.

46. Al Ali AO, Soeid MA, Majrabi Al Agsm MA, Al Jurayyan NA (2016) Hypopituitarism following Traumatic Brain Injury (TBI). Eur J Pharmaceut Med Res 3(6): 77-79.

47. Zengin S (2013) The effects of meningitis on anterior pituitary functions. American Journal of Health Research 1(3): 36-41.

48. Tsiakalos A, Xynos ID, Sipsas NV, Kaltsas G (2010) Pituitary insufficiency after infectious meningitis: A prospective study. J Clin Endocrinol Metab 95(7): 3277-3281.

49. Levy-Shraga Y, Gazit I, Modan-Moses D, Pinhas-Hamiel O (2014) Pituitary function in children following infectious diseases of the central nervous system. Pituitary 17(2): 118-124.

50. Al Issa SD, Al Haboob AA, Al Jurayyan RN, Babiker AM, Al Jurayyan NA (2014) Hypothalamic-pituitary dysfunctions in an infant with streptococcal meningitis. Sch J App Med Sci 2(5F): 1936-1938.

51. Al Ali AO, Hakami SM, Soied MA (2017) Empty sella syndrome in children: The importance of early diagnosis and proper neuroendocrine assessment. EIPMR 4(4): 160-163.

52. De Marinis L, Bonadonna S, Bianchi A, Maira G, Giustina A (2005) Primary empty sella. The Journal of clinical endocrinology and metabolism 90(9): 5471-547.

53. Rani PR, Maheshwari R, Reddy TSK, Prasad NR, Reddy PA (2013) Study of prevalence of endocrine abnormalities in primary empty sella. Indian Journal of Endocrinology and Metabolism 17(Suppl1): S125-S126. 
54. Stanley T (2011) Diagnosis of growth hormone deficiency in childhood. Current opinion in endocrinology, diabetes and obesity 19(1): 47-52.

55. (2000) Consensus guidelines for the diagnosis and treatment of Growth Hormone $(\mathrm{GH})$ deficiency in childhood and adolescence: Summary statement of the GH Research Society. GH Research Society. J Clin Endocrinol Metab 85(11): 3990-3993.

56. Richmond EJ, Rogol AD (2008) Growth hormone deficiency in children. Pituitary 11(2): 115-120.

57. Al-Jurayyan NAM (2016) central adrenal insufficiency in children in a major teaching hospital riyadh, saudi arabia. (Ponte) Int Sci Res J 72(10): 271-276.

58. Grossman AB (2010) Clinical Review: The diagnosis and management of central hypoadrenalism. The J Clin Endocrinol Metab 95(11): 48554863.

59. Krasner AS (1999) Glucocorticoid-induced adrenal insufficiency. Jama 282(7): 671-676

\section{ISSN: 2574-1241}

DOI: $10.26717 / B J S T R .2018 .11 .002081$

Nasir AM Al Jurayyan. Biomed J Sci \& Tech Res

(C) This work is licensed under Creative

Submission Link: https://biomedres.us/submit-manuscript.php
60. Blevins LS, Wand GS (1992) Diabetes insipidus. Critical care medicine 20(1): 69-79.

61. Devin JK (2012) Hypopituitarism and central diabetes insipidus: Perioperative diagnosis and management. Neurosurg Clin N Am 23(4): 679-689.

62. Loh JA, Verbalis JG (2007) Diabetes insipidus as a complication after pituitary surgery. Nat Clin Pract Endocrinol Metab 3(6): 489-494.

63. Lania A, Persani L, Beck-Peccoz P (2008) Central hypothyroidism. Pituitary 11(2): 181-186.

64. Al-Jurayyan NA, Al Issa SD, Al Nemri AM, Al Otaibi HM, Babiker AM (2015) The spectrum of 46XY disorders of sex development in a University centre in Saudi Arabia. J Pediatr Endocrinol Metab 28(9-10): 1123-1127.

BIOMEDICAL
RESEARCHES $\quad \begin{aligned} & \text { Assets of Publishing with us } \\ & \text { - Global archiving of articles }\end{aligned}$

